\title{
'Black Pearl' Thornless Trailing Blackberry
}

Chad E. Finn

U.S. Department of Agriculture, Agricultural Research Service, Horticultural Crops Research Laboratory, Northwest Center for Small Fruit Research, Corvallis, OR 97330

\section{Brian M. Yorgey}

Department of Food Science, Oregon State University, Corvallis, OR 97331

Bernadine C. Strik

Department of Horticulture, Oregon State University, Corvallis, OR 97331

\section{Robert R. Martin}

U.S. Department of Agriculture, Agricultural Research Service, Horticultural Crops Research Laboratory, Northwest Center for Small Fruit Research, Corvallis, OR 97330

\section{Michael Qian}

Department of Food Science, Oregon State University, Corvallis, OR 97331

Additional index words. Rubus sp., fruit breeding, spineless

'Marion' is currently the most important blackberry (Rubus L. subgenus Rubus) cultivar in the world and it is the predominant cultivar grown for the processed fruit market (Finn et al., 1997). While 'Marion' produces fruit of outstanding quality for processing, the plants are thorny (botanically termed spiny). When 'Marion' is machine harvested, thorns can end up in the product (Strik and Buller, 2002), which can lead to a poor product, and, more significant in an economic sense, lawsuits. As a result, a primary priority for the breeding program has been the development of cultivars that are thornless, machine harvestable, and retain the excellent processing characteristics of 'Marion'. Three thornless blackberry cultivars with these qualities are being released simultaneously: 'Black Pearl', 'Black Diamond' (Finn et al., 2005a) and 'Nightfall' (Finn et al., 2005b).

'Black Pearl' is a thornless trailing blackberry from the U.S. Department of AgricultureAgricultural Research Service (USDA-ARS) breeding program in Corvallis, Ore., released in cooperation with the Oregon State University Agricultural Experiment Station and the Washington State University Agricultural Research Center. 'Black Pearl' is thornless, adapted to machine harvesting and has yield and processed fruit quality very similar to 'Marion'.

\section{Origin}

In 1995, 'Black Pearl', tested as ORUS

Received for publication 8 June 2005. Accepted for publication $18 \mathrm{Aug}$. 2005. This research was partially funded by the Oregon Raspberry and Blackberry Commission and the Northwest Center for Small Fruit Research. We gratefully acknowledge the assistance of Mary Peterson, Connie Pace, and Gloria Murray in 'Black Pearl's evaluation; Nola Mosier in obtaining virus-free nuclear stock; and Derek Peacock, formerly with Enfield Farms (Lynden, Wash.), for trial results.
1380-1, was selected in Corvallis, Ore. from a 1993 cross of ORUS $1117-11 \times$ ORUS $1122-1$ (Fig. 1). ORUS 1117-11 was a very promising thornless selection that was very late ripening and whose thornlessness was derived through NC 37-35-M-2 from 'Austin Thornless'. ORUS 1122-1 shares many characteristics with 'Marion' but is higher yielding and larger fruited. Unfortunately, ORUS 1122-1 is only suited for processing and is thorny which became an unacceptable combination in the early 1990s. ORUS 1117-11 and ORUS 1122-1 share many genotypes in their respective pedigrees; R. ursinus Cham. \& Schltdl derivatives such as 'Zielinski', 'Logan', 'Jenner-1', 'Marion' and 'Olallie' are prominent and the eastern blackberry 'Eldorado' ( $R$. allegheniensis hybrid) accounts for nearly $1 / 8$ of 'Black Pearl's background. Flow cytometry estimated 'Black Pearl's ploidy as $2 \mathrm{n}=9 \mathrm{x}=63$ (Meng and Finn, 2002).

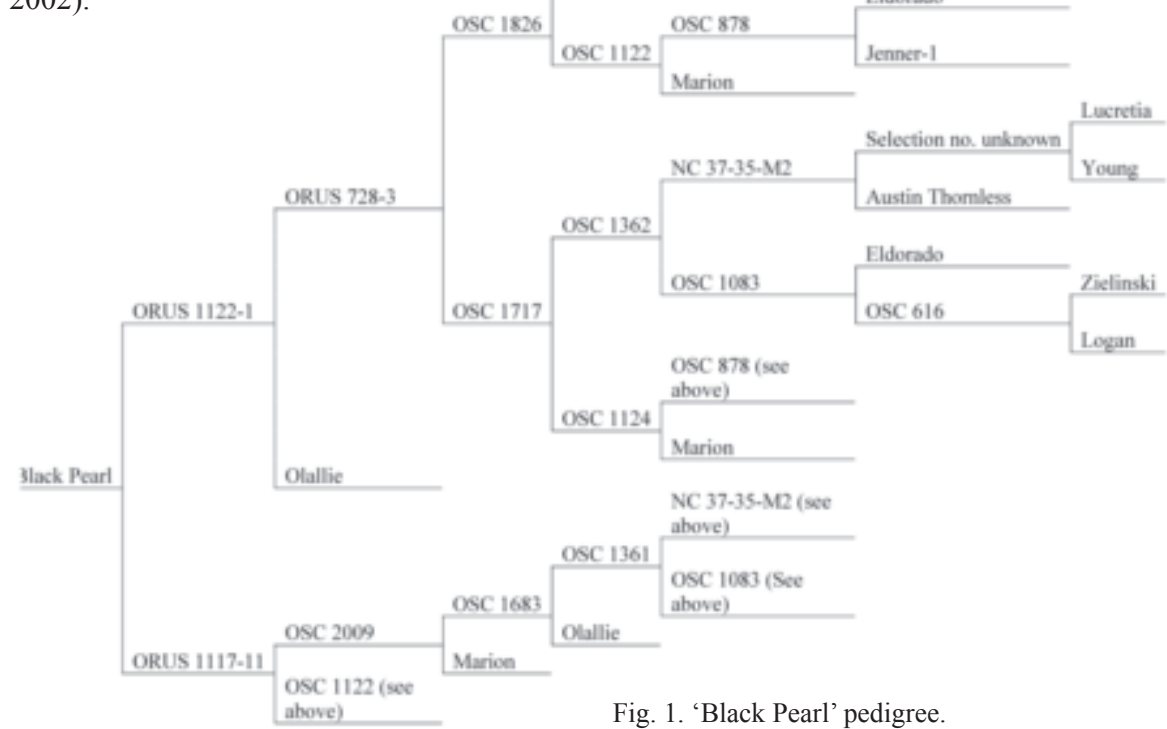

'Black Pearl' has been tested predominantly at the Oregon State University North Willamette Research and Extension Center (NWREC) in Aurora, Ore. In test plantings, standard cultural practices for trailing blackberry production were used, including annual pre- and postemergent herbicide applications, annual spring nitrogen fertilization $(78 \mathrm{~kg} \mathrm{~N} /$ ha), postharvest removal of floricanes, training of primocanes to a two wire trellis, and weekly overhead application of about $2.5 \mathrm{~cm}$ of irrigation. Each of the plantings received applications of dormant season fungicides (liquid lime sulfur and copper hydroxide) to control leaf and cane spot (Septoria rubi Westend.), purple blotch [Septocyta ruborum (Lib.) Petr.], rust [Kuehneola uredinis (Link] Arth.) and anthracnose [Elsinoe veneta (Burkholder) Jenk.]. They also received a single bloom application of captan to control anthracnose, botrytis (Botrytis cinerea Pers.: Fr.), cane spot, purple blotch and stamen blight (Hapalosphaeria deformans [Syd.] Syd.) at labeled rates. In 1997, before evaluation in replicated trial (Table 1), 'Black Pearl' was planted in an unreplicated trial with a number of selections and cultivars (Table 2). The replicated planting at NWREC was arranged in a randomized complete block design, with four, three-plant replications to assess fresh fruit characteristics and three replications hand-harvested once per week to determine harvest season, yield and fruit weight. The average fruit weight for a season is a weighted mean based on the weight of a randomly selected subsample of 25 fruit from each harvest. These data, collected from 2001-03, were analyzed as a split plot in time with cultivar as the main plot and year as the subplot. Of the 23 genotypes harvested in replicated trial for yield, only the data from 'Marion', 'Silvan', and 'Waldo' and the new releases 'Black Pearl', 'Black Diamond' (Finn et al., 2005a), and 'Nightfall' (Finn et al, 2005b) were included in the analysis (PROC GLM; SAS Institute, Cary, N.C.). The cultivar $\times$ year 
Table 1. Fruit weight and yield in 2001-003 for blackberry genotypes planted in 1999 in replicated trial at the Oregon State University-North Willamette Research and Extension Center in Aurora.

\begin{tabular}{|c|c|c|c|c|c|}
\hline \multirow[b]{3}{*}{ Genotype } & \multirow{2}{*}{$\begin{array}{c}\text { Fruit } \\
\text { size }(g)^{z}\end{array}$} & \multicolumn{4}{|c|}{ Yield $\left(\mathrm{kg} \cdot \mathrm{ha}^{-1}\right)$} \\
\hline & & & & & Mean \\
\hline & $\overline{2001-03}$ & 2001 & 2002 & 2003 & $2001-03$ \\
\hline Nightfall & $6.2 \mathrm{~b}$ & $42447 \mathrm{a}$ & $13405 \mathrm{a}$ & $20962 \mathrm{a}$ & $25604 \mathrm{a}$ \\
\hline Silvan & $6.2 \mathrm{bc}$ & $31757 \mathrm{ab}$ & $16811 \mathrm{a}$ & $21485 \mathrm{a}$ & $23351 \mathrm{a}$ \\
\hline Black Diamond & $5.8 \mathrm{~cd}$ & $29281 \mathrm{a}-\mathrm{c}$ & $15568 \mathrm{a}$ & $19001 \mathrm{a}$ & $21283 \mathrm{ab}$ \\
\hline Marion & $5.1 \mathrm{e}$ & $26380 \mathrm{a}-\mathrm{c}$ & $13021 \mathrm{a}$ & 18397 a & $19266 \mathrm{ab}$ \\
\hline Black Pearl & $6.2 \mathrm{~b}$ & $26969 \mathrm{a}-\mathrm{c}$ & 14373 a & $15505 \mathrm{ab}$ & $18949 a b$ \\
\hline Waldo & $5.5 \mathrm{~d}$ & $25849 \mathrm{bc}$ & $11000 \mathrm{a}$ & $17286 \mathrm{a}$ & $18045 \mathrm{ab}$ \\
\hline Siskiyou & $6.9 \mathrm{a}$ & $20969 \mathrm{c}$ & $9854 \mathrm{a}$ & $9359 \mathrm{~b}$ & $13394 \mathrm{~b}$ \\
\hline
\end{tabular}

${ }^{2}$ Means withing a column followed by the same letter are not significantly different $p>0.05$, by Duncan's multiple range test.

Table 2. Average fruit size, yield and harvest season in 1999-2000 for four blackberry cultivars in an unreplicated trial planted in 1997 at the Oregon State University-North Willamette Research and Extension Center in Aurora.

\begin{tabular}{lccccc}
\hline & $\begin{array}{c}\text { Fruit } \\
\text { Genotype }\end{array}$ & $\begin{array}{c}\text { Yield } \\
\left(\mathrm{kg} \cdot \mathrm{ha}^{-1}\right)\end{array}$ & \multicolumn{3}{c}{ 2003 Harvest season } \\
\cline { 4 - 6 } & size $(\mathrm{g})$ & 23579 & 14 July & 1 Aug. & 26 Aug. \\
Waldo & 4.8 & 19896 & 9 July & 14 July & 28 July \\
Marion & 4.8 & 15038 & 6 July & 16 July & 8 Aug. \\
Black Pearl & 6.1 & 13323 & 6 July & 18 July & 28 July \\
\hline Kotata & 4.4 & 1323
\end{tabular}

interaction was significant for yield but not for fruit weight. Therefore, the interaction means for yield are presented and compared using Duncan's multiple range test (Table 1). The fruit ripening season in Ore. was characterized by the dates at which $5 \%, 50 \%$, and $95 \%$ of the total fruit yield were harvested (Table 3). Subjective fruit evaluations were made during the fruiting season using a 1 to 9 scale $(9=$ the best expression of each trait) (Table 4). These subjective evaluations were done on cultivars in the replicated trial as well as important commercial cultivars ('Chester Thornless' and 'Kotata') that were not. The fruit ratings included firmness (as measured subjectively by hand in the field on six to eight berries), color, shape (with a uniform, long conic ideal), texture (as measured subjectively when chewed while tasting berries in the field), separation (subjective rating of how easily ripe fruit separated from the plant), and flavor (subjectively rated by tasting berries in the field) (Table 4). Plant ratings were conducted one time each year from 2001-03 during the fruiting season for primocane and floricane vigor, spines ( $9=$ spineless; cultivars derived from 'Austin Thornless' are seldom completely spineless, basal spines are common and occasionally a single spine on the lower side of the petiolule), and flowering/fruiting lateral length $(1=$ very short, $5=$ very long $)$ and strength ( 1 = weak, droopy; $5=$ stiff, sturdy $)$ (Table 4). In 2004, fruit were harvested by an over-the-row harvester (Littau, Stayton, Ore.) with a horizontal (Christy) head from a large number of genotypes each planted in 2003 in a single five-plant plot at Enfield Farms (Lyn- den, Wash.). In separate studies, the chemical characteristics of commercial cultivars and several advanced selections including 'Black Pearl' were evaluated (Siriwoharn et al., 2004). Yorgey and Finn (2005) prepared individually quick frozen (IQF) and puree products from several genotypes for evaluation by a blind panel of untrained experts.

In Oregon, 'Black Pearl' had a similar yield to all of the cultivars tested including 'Marion' in replicated trial (Table 1). While not statistically different, 'Black Pearl' tended to have a higher yield than 'Siskiyou' in all years, 'Marion' and 'Waldo' in 2 of 3 years, and lower than 'Silvan' in all years. In the original observation plot, 'Black Pearl'had yields intermediate between 'Marion' and 'Kotata' that would suggest comparable commercial yields (Table 2). In the Washington State trial, 'Black Pearl' machine harvested well, yielding a good-looking product with few defective fruit, e.g., green, pedicel-calyx not detached from fruit. Fruit size for 'Black Pearl' tends to be larger than 'Marion', 'Waldo', and 'Kotata', more similar to 'Silvan' but not as large as 'Siskiyou' (Tables 1 and 2).

'Black Pearl'harvest begins the first few days of July, peaks in early July and is largely done by the third week of July in Oregon (Tables 2 and 3 ). The harvest season is almost identical to 'Marion', later ripening than 'Obsidian' and 'Metolius' and is much earlier than 'Waldo'. The earlier evaluation in unreplicated trial had similarly put 'Black Pearl's season as comparable to 'Marion's (Table 2).

Fruit of 'Black Pearl' are similar in shape to 'Marion'; they are a medium long conic and can have a blunt tip (Table 3, Fig. 2). The drupelet arrangement is uneven, similar to 'Marion' and not as uniform as with 'Waldo' or 'Black Diamond' fruit. 'Black Pearl' is only slightly better than 'Marion' for fresh fruit firmness, but it is much better than 'Silvan' (Table 4). Fruit firmness is sufficient such that when the fruit are machine harvested the fruit is similar in quality to 'Marion'. 'Black Pearl' fruit are similar in color to 'Marion' and are much less purple or more black than those of 'Silvan' (Table 3). The fruit separate from the plant easily by hand (Table 3 ) or by machine. As a fresh fruit, 'Black Pearl' has excellent flavor and has a texture similar to 'Marion' or 'Silvan'.

Siriwoharn et al. (2004) evaluated 11 genotypes including 'Black Pearl' for total soluble solids, titratable acidity, total phenolics, total anthocyanins, polyphenolic content, oxygen radical absorbance capacity (ORAC), and ferric reducing antioxidant power(FRAP). 'Black Pearl' fruit had similar total soluble solids to 'Marion', 'Silvan', 'Thornless Evergreen' and 'Waldo' and greater soluble solids than fruit of 'Chester Thornless'. The total titratable acidity for 'Black Pearl' was similar to that of 'Marion' and 'Silvan', but less than 'Waldo' and much greater than 'Chester Thornless' and 'Thornless Evergreen'. Total phenolic content and FRAP values for 'Black Pearl' fruit were similar to those for 'Marion' but the total anthocyanin levels and ORAC values were less. While the proportion of polyphenolics varied greatly among genotypes in their study, 'Black Pearl' had procyanidin values much greater than 'Marion' but the ellagitannin, flavonol and ellagic acid levels were comparable to those of 'Marion'. The anthocyanin profile for 'Black Pearl' fruit was very similar to that of 'Marion for cyanidin 3-glucoside and cyanidin 3-rutinoside but the levels of cyanidin-containing xylose and total monomeric anthocyanins (expressed as mg cyanidin-3-glucoside/ $100 \mathrm{~g}$ fresh weight) were lower than those for 'Marion' (Siriwoharn et al., 2004).

'Black Pearl' and other new cultivars were evaluated by a blind panel as IQF and puree samples (Yorgey and Finn, 2005). As an IQF fruit, 'Black Pearl' was ranked higher than 'Marion', 'Silvan', and 'Waldo' for color, appearance, and seediness and it was ranked similar to 'Marion', but higher than 'Silvan' and 'Waldo', for flavor and "overall quality". As a pureed product, 'Black Pearl' was ranked similarly to 'Silvan', 'Waldo', and 'Marion' for aroma, flavor, color and overall quality. 'Black Pearl'will produce an excellent processed product based on the combination of input from these panels and other informal evaluations.

'Black Pearl' plants are similar in vigor and

Table 3. Mean scores for subjectively evaluated characteristics ${ }^{z}$ of 'Black Pearl' and three commercial blackberry cultivars planted in 1999 at the Oregon State University-North Willamette Research and Extension Center in Aurora.

\begin{tabular}{|c|c|c|c|c|c|c|c|c|c|c|c|}
\hline \multirow[b]{2}{*}{ Cultivar } & \multirow{2}{*}{$\begin{array}{l}\text { Primocane } \\
\text { vigor }\end{array}$} & \multirow[b]{2}{*}{ Thorns } & \multirow{2}{*}{$\begin{array}{c}\text { Floricane } \\
\text { vigor }\end{array}$} & \multicolumn{2}{|c|}{ Fruiting lateral } & \multicolumn{6}{|c|}{ Fruit } \\
\hline & & & & Length & Strength & Firm & Color & Shape & Texture & Separation & Flavor \\
\hline Marion & 9.0 & 4.6 & 8.5 & 4.8 & 3.3 & 5.4 & 8.3 & 6.7 & 8.9 & 8.9 & 8.6 \\
\hline
\end{tabular}

${ }^{2}$ Characteristics (except for laterals) scored on a 1 to 9 scale, where $1=$ the poorest expression of the trait and $9=$ the best expression of the trait, i.e., $9=$ very vigorous, spineless, very firm, black, uniform shape, pleasant to chew not seedy, separates easily from the plant, and intense flavor, respectively. Lateral characteristics scored on a 1 to 5 scale, where $1=$ short or weak laterals and $5=$ long or strong laterals. 

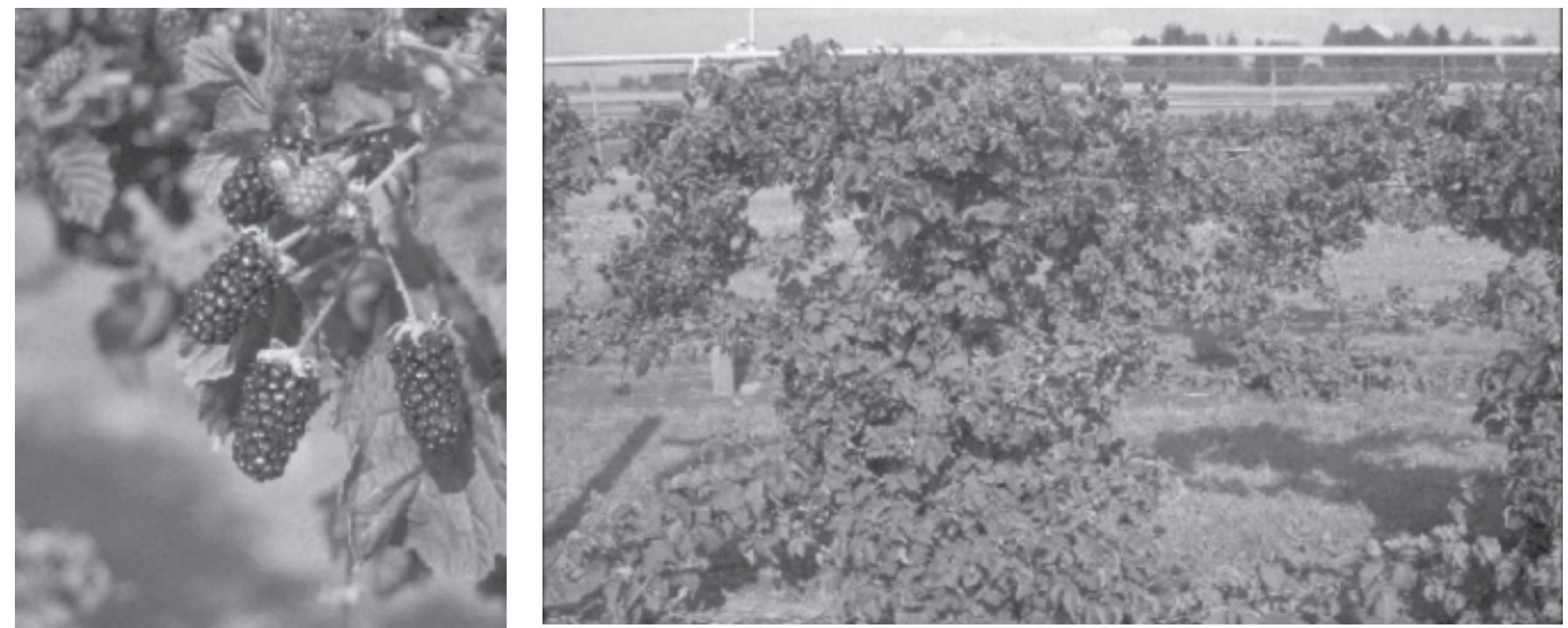

Table 4. Mean ripening season and date at which the yield of each genotype reached the given percentage of total yield at the Oregon State University-North Willamette Research and Extension Center in Aurora. Trial was planted in 1999 and harvested in 2001-03.

\begin{tabular}{lccc}
\hline & \multicolumn{3}{c}{ Harvest season } \\
\cline { 2 - 4 } Genotype & $5 \%$ & $50 \%$ & $95 \%$ \\
\hline Metolius & 25 June & 3 July & 14 July \\
Obsidian & 25 June & 4 July & 15 July \\
Siskiyou & 25 June & 8 July & 25 July \\
Silvan & 26 June & 8 July & 21 July \\
Black Diamond & 28 June & 8 July & 21 July \\
Marion & 3 July & 10 July & 22 July \\
Black Pearl & 3 July & 11 July & 24 July \\
Nightfall & 3 July & 22 July & 23 July \\
Waldo & 8 July & 7 Aug. \\
\hline
\end{tabular}

cane health to 'Marion' and 'Silvan' (Table 3) although the cane length tends to be less in 'Black Pearl'. 'Black Pearl' is thornless by commercial standards, however the primocanes have some thorns on the basal 30 to $40 \mathrm{~cm}$, a height below the catcher plates on a harvest machine; 'Black Pearl is comparable to 'Waldo' in this trait (Table 3). 'Black Pearl' has fruiting laterals that are medium in length, shorter than those of 'Marion'but longer than those of 'Waldo'. The laterals tend to be similar in strength to those of 'Marion'. Plants of 'Black Pearl', pruned to a similar number of canes as 'Marion' and 'Kotata', have a more open, less-dense plant habit.

In our trials, under a minimal spray program, 'Black Pearl' has been free of serious cane, leaf or fruit diseases. 'Black Pearl' is not particularly susceptible to Septoria leaf spot and purple blotch. 'Black Pearl' does not exhibit vegetative or fruit symptoms of cane and leaf rust. In some years, particularly 1997, 'Marion', 'Kotata', and 'Black Butte' were severely damaged by a dryberry syndrome. The cause of this problem is not known currently but is suspected to be a complex of diseases, particularly anthracnose, that develops under certain combinations of temperature and moisture. 'Black Pearl' has not shown symptoms of dryberry in our trials nor has it been noted in grower fields.

No significant winter injury has been noted on this genotype since it was selected in 1997. However, the winters, even those of northern
Washington, have been mild. In Fall 2003, the temperatures dropped rapidly to -3 to $-6{ }^{\circ} \mathrm{C}$ in Oregon and -4 to $-8^{\circ} \mathrm{C}$ in northern Wash. the last two days of October. Many genotypes including 'Marion' and 'Silvan', but not 'Black Pearl', were severely damaged (cane and bud death) by this rapid change in temperature in our Washington, but not our Oregon, trials. One reason for the greater damage in Washington may be that the plots were in a commercial red raspberry field where plants were heavily fertilized with nitrogen and irrigated to maximize growth the first year and yield the following year. This approach may have led to injury on plants that were not yet dormant. Nonetheless, 'Black Pearl' came through this episode with much less damage than 'Marion'.

Outstanding characteristics of 'Black Pearl' include large fruit, a yield similar to that of 'Marion', excellent processed fruit quality, excellent adaptation to machine harvesting, and thornless plants with good disease tolerance. 'Black Pearl' should be a useful commercial cultivar for the processed blackberry industry. 'Black Pearl' will not likely be well suited for the fresh market as it is too soft, but this cultivar is suited for homeowners. 'Black Pearl' is expected to perform well in areas where trailing blackberries are adapted, including the Pacific Northwest, California, Chile, New Zealand, United Kingdom, and the Mediterranean region.
Fig. 2. 'Black Pearl' (above left) fruiting lateral and (above right) plant.

\section{Availability}

'Black Pearl' is not patented. When this germplasm contributes to the development of a new cultivar or germplasm, the authors request that appropriate recognition be given to the source. 'Black Pearl' nuclear stock has tested negative for tomato ringspot, raspberry bushy dwarf, and tobacco streak viruses by ELISA and has indexed negative on grafting to $R$. occidentalis. Further information or a list of nurseries propagating 'Black Pearl' is available on written request to the contact author. The USDA-ARS does not have commercial quantities of plants to distribute. In addition, plants of 'Black Pearl' have been deposited in the National Plant Germplasm System, at the USDA-ARS NCGR in Corvallis, accession number PI 638260, where it is available for research purposes, including development and commercialization of new cultivars.

\section{Literature Cited}

Finn, C.E., B.M. Yorgey, B.C. Strik, R.R. Martin, and M.C. Qian. 2005b. 'Black Pearl'thornless trailing blackberry. HortScience 40:2179-2181.

Finn, C.E., B.M. Yorgey, B.C. Strik, R.R. Martin, and M.C. Qian. 2005a. 'Nightfall' thornless trailing blackberry. HortScience 40:2182-2184.

Finn, C., B.C. Strik, and F.J. Lawrence. 1997. Marion trailing blackberry. Fruit Var. J. 51:130-132.

Meng, R. and C. Finn. 2002. Determining ploidy level and nuclear DNA content in Rubus by flow cytometry. J. Amer. Soc. Hort. Sci. 127:767-775.

Siriwoharn, T, R.E. Wrolstad, C.E. Finn, and C.B. Pereira. 2004. Influence of cultivar, maturity and sampling on blackberry (Rubus L. hybrids) anthocyanins, polyphenolics, and antioxidant properties. J. Agr. Food Chem. 52:8021-8030.

Strik, B. and G. Buller. 2002. Reducing thorn contamination in machine-harvested 'Marion'blackberry. Acta Hort. 585:677-681.

Yorgey, B.M. and C.E. Finn. 2005. Comparison of 'Marion' to thornless blackberry genotypes as individually quick frozen and puree products. HortScience 40:513-515. 